\title{
MEMÓRIA INDIVIDUAL E COLETIVA EM 'THE REMAINS OF THE DAY' DE KAZUO ISHIGURO
}

\author{
Tiago Ferreira Pereira ${ }^{1}$ \\ Rosani Ketzer Umbach ${ }^{2}$
}

\begin{abstract}
Resumo: $\mathrm{O}(\mathrm{s})$ romance(s) de Kazuo Ishiguro coloca(m) em questão a memória humana - sua capacidade, confiabilidade, falibilidade e combustibilidade assim como, sua representação em uma esfera individual, coletiva e cultural. Em The remains of the day (1989), Ishiguro confronta o leitor com a figura de Stevens que constrói uma narrativa do "eu" por meio de um processo de rememoração. Como a memória de Stevens aparece distante das recordações levantadas por outras testemunhas, lidar com a confiabilidade desse narrador-personagem tratando-se da reconstrução de um passado histórico se torna problemático. Este trabalho pretende oferecer uma leitura sobre o tema da memória no romance The remains of the day, de Kazuo Ishiguro, com enfoque na sua representação individual e coletiva - isso, por meio, principalmente, da teoria de Maurice Halbwachs sobre a memória individual e coletiva. Esse diálogo evidencia que a dimensão social tem efeito sobre a forma como o protagonista relembra sua própria estória e configura o passado do(s) Outro(s).

Palavras-chave: Confiabilidade; literatura de língua inglesa; memória.
\end{abstract}

\begin{abstract}
Absubstract: The novel(s) of Kazuo Ishiguro puts into question the human memory - the capacity, reliability, fallibility, and combustibility - as well as its representation in an individual, collective and cultural sphere. In The remains of the day (1989), Ishiguro confronts the reader with the figure of Stevens, who constructs a narrative of the "I" through a process of recollection. Given that Stevens's memory appears far distant from the recollections of other witnesses, to deal with the reliability of this character narrator in the reconstruction of a historical past becomes an issue. This paper intends to offer a reading on the theme of memory in Kazuo Ishiguro's novel, The remains of the day, focusing on its individual and collective representation, this mainly through Maurice Halbwachs' theory of individual and collective memory. The dialogue demonstrates that the social dimension has an effect on how the protagonist recalls his own story and shapes the past of the Other(s).
\end{abstract}

Keywords: Reliability; English literature; memory.

\footnotetext{
1 Mestrando no Programa de Pós-Graduação em Letras da UFSM. Bolsista CAPES. E-mail: tiagoberesford@hotmail.com 2 Professora do Programa de Pós-Graduação em Letras da UFSM. Bolsista CNPq. E-mail: rosani.umbach@ufsm.br
} 
O tema da memória tem se destacado, no campo literário, em razão de uma onda crescente de publicações que vem movimentando o mercado editorial, como, por exemplo: diários de guerra, (auto)biografias, relatos de viagem, etc. Essa procura pelo público leitor também vem acompanhado por um interesse progressivo de pesquisadores e críticos literários em tentar dialogar com esses gêneros literários. Para a pesquisadora Astrid Erll (2008), a memória é uma problemática de estudo que se estende a outros campos de pesquisa e, por isso, é frutífera a uma abordagem interdisciplinar. No entanto, não se deve pensar nela como um fenômeno inteiramente recente ou pertinente unicamente ao séc. XX e XXI. Pelo contrário, a memória e seus desdobramentos já eram abordados na Antiguidade Clássica por filósofos como Aristóteles (2019), por exemplo, em seu texto Da memória e da reminiscência. Ela também aparecia nas artes, nos épicos de Homero (2013) e de Virgílio (2016) - respectivamente, A ilíada e A eneida. Em comparação, no século XX, observa-se que a memória obteve um destaque maior ainda, principalmente, se mencionados os relatos de campos de concentração nazista ou de perseguição durante a Ditadura Militar no Brasil. Para o historiador Jay Winter (2006), fica evidente que o tema da Shoah tem motivado a reflexão sobre os desdobramentos da memória. O que, também, estaria fomentando esse boom em torno da memória, segundo o autor, são fatores como: o desenvolvimento social, cultural, medicinal e econômico em certos espaços sociais que torna possível a pesquisa e o diálogo com esse tema: a memória. Birgit Neumann (2008), também pesquisadora no campo dos Estudos Culturais da Memória, destaca que: "The study of literary representations of individual processes of memory has always been one of the central epistemological interests in literary studies". (NEUMANN, 2008, p. 333). ${ }^{3}$ No entanto, apenas em anos recentes que a Academia tem se preocupado em investigar as representações da memória coletiva (NEUMANN, 2008). O termo memória coletiva foi elaborado pelo sociólogo Maurice Halbwachs na primeira metade do século XX. Halbwachs, na época, mostrava-se preocupado em discutir sobre os contextos sociais da memória. Em virtude de seu esforço intelectual, Halbwachs (2017), em A memória coletiva, diferenciou a memória individual de sua esfera coletiva e considerou ambas como construções sociais suscetíveis à influência de espaços sociais como grupos, comunidades ou, até mesmo, de sociedades inteiras. Astrid Erll (2008) fala em três concepções de memória que estão presentes atualmente nos estudos literários. Dentre elas, está a memória como mimese, ou seja, a memória como encenação no texto literário que é o interesse central deste artigo.

Entre alguns escritores do século XXI que poderiam servir de objeto de estudo para a compreensão de como os processos de rememoração ocorrem na ficção, encontra-se Kazuo Ishiguro: romancista britânico e de origem japonesa (Nagasaki - 1954). Ishiguro ficou mundialmente reconhecido após receber o Nobel Prize in Literature (2017). Segundo o crítico Brian W. Shaffer (1998), Ishiguro é um dos escritores mais representativos do que poderia ser visto como um cânone da literatura inglesa contemporânea.

Kazuo Ishiguro, no entanto, prefere autodenominar-se não como pertencente a um projeto de literatura nacional (a inglesa), mas como um escritor representante da literatura

3 "O estudo das representações literárias de processos individuais da memória sempre foi um dos interesses epistemológicos centrais nos estudos literários.” (NEUMANN, 2008, p. 333, tradução livre). 
"internacional". Nas palavras dele: "I had no clear role, no society or country to speak for or write about. Nobody's history seemed to be my history." (ISHIGURO, 1989, apud MIYOSHI et al., 1993, p. 169). ${ }^{4}$ Já em relação ao seu estilo, ao mesmo tempo que empreendem uma linguagem versátil, seus textos também exibem uma densidade emocional capaz de envolver o leitor de uma forma intensa. Além disso, uma qualidade bastante comum a todos os seus romances é o emprego de narradores em primeira pessoa, reconhecidos pela sua não confiabilidade. A confiabilidade ou não do narrador é um dos objetos de análise nos Estudos Culturais da Memória (RAY, 2017). Geralmente, esses narradores-personagens possuem algo a esconder, mas falham nesse sentido ao reconstruírem uma narrativa que atesta seus próprios fracassos. Outra particularidade da escrita de Ishiguro é o constante retorno de seus protagonistas ao passado por meio de um quadro de memórias recriado por eles. Consequentemente, evoca-se um sentimento de nostalgia, hora de arrependimento, hora de melancolia (SHAFFER, 1998). É possível identificar essas e outras características em seu romance The remains of the day.

O romance The remains of the day (1989) foi ganhador do Man Booker Prize do mesmo ano, e é um dos textos mais excepcionais de Ishiguro, segundo a crítica especializada em sua obra. Conforme Shaffer (1998), esse romance: "[...] represents a refinement and perfection of the narrative techniques and psychological portraits of its two predecessors." (SHAFFER, 1998, p. 4). O protagonista é o metódico Stevens, (SHAFFER, 1998, p. 4). ${ }^{5}$ O protagonista é o metódico Stevens, mordomo por mais de três décadas da mansão Darlington Hall na Inglaterra. No verão de 1956, Stevens empreende uma viagem de Ford pelo Oeste Inglês. Durante o percurso, rememora sua trajetória de vida exclusivamente dedicada à profissão de mordomo em Darlington Hall. Desse modo, durante o percurso de seis dias em que Stevens viaja, o leitor visita uma parte do passado do protagonista e da Inglaterra, uma viagem no tempo por duas guerras mundiais e um amor não realizado entre o mordomo e sua ex-governanta, Kenton. Essa viagem, compreendida em um primeiro plano, por Stevens, como uma missão a trabalho, torna-se a ocasião perfeita para revisitar momentos chave de seu passado, refletir sobre como a lealdade a seu antigo patrão, Lorde Darlington, tivera um peso decisivo sobre as circunstâncias presentes de sua vida. Ou seja, o protagonista debruça-se sobre questões que envolvem desde sua identidade até experiências de trauma. Embora a voz de Stevens pareça precisa nas descrições, é importante salientar que o narrador-personagem articula sua voz de modo a convencer o leitor e obter a aprovação deste. Ademais, esse romance trata da busca por algo que está irrevogavelmente perdido (o tempo), uma história que expõe a influência da(s) memória(s) sobre o indivíduo tratando, portanto, de sua confiabilidade ilusória. Na viagem de Stevens pelo Oeste, os flashbacks ocorrem em um fluxo que surpreende pela acuracidade com que são colocados. A suposta "veracidade", dentro do universo diegético da obra, sobre os fatos/eventos é representada de forma inquietante.

4 "Eu não tenho nenhum papel claro, nenhuma sociedade ou país em cujo nome falar ou sobre o qual escrever." (ISHIGURO, 1989, apud MIYOSHI et al., 1993, p. 169, tradução livre).

5 “[...] representa um refinamento e perfeição das técnicas narrativas e retratos psicológicos de seus dois antecessores." (SHAFFER, 1998, p. 4, tradução livre). 
De fato, o(s) romance(s) de Ishiguro coloca $(m)$ em questão a memória humana - sua capacidade, confiabilidade, falibilidade e combustibilidade, assim como, sua representação em um nível individual, coletivo e cultural. Quanto a uma definição, para o pesquisador Ivan Izquierdo (2011, p. 11), "Memória significa aquisição, formação, conservação e evocação de informações”. Evocação, nesse sentido, tem a ver com recordação ou lembrança. Izquierdo (2011, p. 14) conceitua que a memória em seu sentido amplo: “[...] abrange desde os ignotos mecanismos que operam nas placas de meu computador até a história de cada cidade, país, povo ou civilização, incluindo as memórias individuais dos animais e das pessoas”. Enquanto que, para Joël Candau (2011), a memória é uma reconstrução continuamente atualizada do passado, ao contrário de um reflexo fiel dele mesmo. Essas definições se tornam importantes para o entendimento de como a narração de Stevens pode estar equivocada diante da imagem criada por ele do passado. Para Maurice Halbwachs (2017, p. 19), "Recorremos a testemunhos para reforçar ou enfraquecer e também para completar o que sabemos de um evento sobre o qual já temos alguma informação". No caso de The remains of the day, as testemunhas aparecem para enfraquecer o que é em parte rememorado pelo narrador-personagem. É a influência do social sobre a memória sendo representada no romance, ou seja, a influência de outros vetores na reconstrução de um quadro do passado. $\mathrm{Na}$ visão de Halbwachs (2017, p. 30), as memórias de cada indivíduo jamais se fecham nele mesmo pois as lembranças "[...] permanecem coletivas e nos são lembradas por outros, ainda que se trate de eventos em que somente nós estivemos envolvidos e objetos que somente nós vimos". Nesse sentido, o quadro que representa a memória individual do personagem Stevens também contribui com um quadro da representação da memória coletiva, principalmente sobre o período das duas grandes guerras mundiais (1914-1918 e 1939-1945). Se tratando disso, para Jean Duvignaud (2017, p. 13), como colocado no "Prefácio" de A memória coletiva de Halbwachs, sua teoria "[...] ajuda a situar a aventura pessoal da memória [...] que resulta de mudanças que ocorrem nas nossas relações com os grupos a que estamos misturados e nas relações que se estabelecem nesses grupos”. Stevens transita por pontos históricos estratégicos no combate do exército inglês aos nazistas durante a II Guerra Mundial: partindo de Darlington Hall (casa antiga do Tratado de Versalhes) para Weymouth (famosa por ter ajudado a lançar a ofensiva do Dia-D sobre os nazistas). Diante disso, é imprescindível para a compreensão do texto entender como a memória individual de Stevens dialoga com a memória advinda de outros vetores para a reconstrução de um quadro coletivo acerca do passado.

Até o momento presente, outros críticos literários já empregaram esforço intelectual em dialogar com o romance The remains of the day de Kazuo Ishiguro. Dentre os trabalhos consultados estão os de Granja (2006), Usui (2005), Johanson (2011), Iversen (2014) e Ray (2019). No entanto, nenhuma pesquisa centrou sua discussão nos pressupostos teóricos, especialmente os levantados por Maurice Halbwachs e Joël Candau, por exemplo. Além disso, segundo Antoine Compagnon (2014), é papel da crítica literária oferecer um discurso acerca das obras. Ela acentua a experiência da leitura: “[...] [A crítica literária] descreve, interpreta, avalia o sentido e o efeito que as obras exercem." (COMPAGNON, 2014, p. 21). Tendo isso em mente, este trabalho pretende oferecer uma leitura sobre o tema da memória no romance The remains of the day, de Kazuo Ishiguro, com enfoque na sua representação 
individual e coletiva. Alguns questionamentos empreendidos na leitura desse texto são: 1) por que a memória de Stevens parece estar tão distante das recordações levantadas por outras testemunhas; 2) como o contato com o social, ou seja, o coletivo, afeta as lembranças de Stevens; 3) como lidar também com a confiabilidade desse narrador, se tratando de uma reconstrução de um passado histórico? Este artigo discute The remains of the day, por meio de pressupostos teóricos levantados por Candau (2011), Erll \& Nünning (2008), Halbwachs (2017), Izquierdo (2011) e Neumann (2008), dentre outros.

\section{MEMÓRIA EM 'THE REMAINS OF THE DAY'}

Aparentemente, o que levou Kazuo Ishiguro ao exercício da escrita foi a tentativa de resgatar e preservar no papel algumas das poucas lembranças que possuía de sua infância em sua cidade natal no Japão. Em The remains of the day, encontra-se um exercício semelhante; o protagonista narra sua trajetória em formato de diário: "And let me tell you, if you were to have come into our servants' hall on any of those evenings." (ISHIGURO, 1989, p. 18). ${ }^{6}$ É desse modo que Stevens endereça ao leitor sua narrativa - utilizando-se de uma linguagem formal em todo o espaço do universo diegético por onde transita. Esse é apenas um dos aspectos que revela sua incapacidade de abandonar o véu de sua profissão. Além disso, a forma como Stevens articula seu testemunho revela preocupação em ser mal interpretado ou até mesmo julgado pelo leitor. É como se o narrador-personagem esperasse a aceitação de seu relato mesmo que para isso tenha que ocultar fatos/eventos na construção de um quadro do passado. No entanto, o protagonista descobre que outros personagens possuem ideias e visões de mundo divergentes da dele. E é com o foco nesse choque entre o relato de Stevens e o de outros personagens periféricos que Ishiguro explora os confins da memória, principalmente, a relação entre memória individual e coletiva. Como observado por Shaffer (1998), os romances de Ishiguro centram em protagonistas que não possuem nenhuma compreensão sobre o que é a vida, ou seja, que não conseguem enxergar fora dos círculos em que aparecem aprisionados.

Stevens dedicou-se, exclusivamente, à profissão de mordomo, por muitos anos, de forma que negou atenção a outras esferas de sua vida, como a pessoal. O narrador-personagem não permitiu que assuntos de outra natureza viessem a desviá-lo de seus objetivos profissionais - seu relacionamento frustrado com a ex-governanta Kenton ou a falta de comunicação com seu pai, Sr. Williams Stevens. Representação disso é ilustrada na reação de Stevens à morte de seu pai: "[...] don't think me unduly improper in not ascending to see my father in his deceased condition just at this moment [...] my father would have wished me to carry on just now." (ISHIGURO, 1989, p. 106). ${ }^{7}$ O protagonista acredita ter tornado-se digno de merecer o

6 "E permita-me que lhe conte que se você tivesse entrado dentro de uma das alas dos criados em qualquer uma daquelas noites.” (ISHIGURO, 1989, p. 18, tradução livre. A tradução das demais citações desta obra também são de minha autoria - T. F. P.).

7 “[...] não pense em mim como se eu estivesse agindo de forma inapropriada ao não subir para ver meu pai em sua condição de morto [...] meu pai desejaria que eu permanecesse trabalhando.” (ISHIGURO, 1989, p. 106). 
status de "um grande mordomo" ao ter agido de forma fria e contida ao saber sobre a notícia da morte de seu pai. A dignidade para Stevens só pode ser alcançada pela capacidade de um mordomo nunca abandonar o seu "eu" profissional. Ou seja, essa dedicação exclusiva é para o narrador-personagem o que atribui grandeza à sua profissão: “[...] 'dignity' has to do crucially with a butler's ability not to abandon the professional being he inhabits." (ISHIGURO, 1989, p. 42). ${ }^{8}$ A questão da dignidade é um dos pontos chave para que se possa compreender o porquê de Stevens ser tão assombrado pelo seu passado e o porquê de suas recordações aparecerem tão distantes dos fatos/eventos recordados por outros vetores da memória. Nesse sentido, o círculo social em que Stevens se fechou contribuiu diretamente tanto para a construção do seu "eu" quanto para a forma como passou a rememorar o passado. Por detrás das paredes de Darlington Hall, tornou-se impossível para o narrador-personagem ter acesso a outras formas de conceber a realidade senão por meio das visões de mundo de uma classe de aristocratas e políticos influentes. Para Candau (2011, p. 16): "A memória, ao mesmo tempo em que nos modela, é também por nós modelada." Esse é apenas um dos exemplos de como o meio social em que Stevens habita tem efeito direto na forma como esse narrador-personagem age ao recordar o passado. De forma metafórica, as paredes e os muros de Darlington Hall encerram a consciência de Stevens de forma que o protagonista sofra as influências dessa redoma, impossibilitando-o de ver além de si mesmo.

Os mordomos, na hierarquia das mansões inglesas, ocupavam o topo da pirâmide social entre os empregados, sendo responsáveis por gerenciar e atribuir tarefas a um esqueleto imenso de outros subordinados. Tendo em vista o que era esperado de um mordomo inglês em meados do séc. XX em relação a Stevens, a extensão de suas ações parece caminhar unicamente em direção àquilo que ele compreende como "o esperado de seu papel como mordomo", como servente de Lorde Darlington, e, posteriormente, de Farraday. Como consequência, Stevens encena personalidades diferente com o intuito de agradar a cada pessoa com quem se encontra. Esse aspecto da identidade de Stevens é ressaltado por uma personagem secundária: "At one point during dinner, Stevens, I would have sworn you were at least three people,'[...]." (ISHIGURO, 1989, p. 107) ${ }^{9}$. Outro exemplo, diz respeito a preocupação excessiva de Stevens em agradar a Farraday quando esse conta-lhe uma piada: "I remain rather unsure as to how I should respond." (ISHIGURO, 1989, p. 14). ${ }^{10}$ Nesse trecho, o narrador-personagem encontra dificuldade em gracejar com seu patrão e imagina como seria a forma mais adequada de responder a uma piada sem parecer ambíguo. No entanto, esse esforço torna-se em vão visto que é esperado que o protagonista reaja com naturalidade, o que ele é incapaz de performar. A questão é que Stevens parece não saber como circular por contextos sociais sem abandonar sua identidade de mordomo - de contenção e servilismo. Isso tem uma grande influência sobre a forma como esse narrador-personagem escolhe então rememorar.

8 “[...] 'dignidade' tem a ver essencialmente com a habilidade que um mordomo possui de não abandonar seu 'eu' profissional que ele habita." (ISHIGURO, 1989, p. 42).

9 “'Em certo ponto durante o jantar, Stevens, eu poderia jurar que você era pelo menos três pessoas,'[...].” (ISHIGURO, 1989, p. 107).

10 “Eu ainda permaneço não tão certo de como devo reagir." (ISHIGURO, 1989, p. 14). 
É importante lembrar que a cultura dos mordomos sofreu com os abalos político-econômicos oriundos da I e II Guerras Mundiais, como lembrado por Jeremy Musson (2010):

Although many houses continued to employ staff in the same numbers as before [...] gradually these numbers were eroded, with new shocks following taxation, inflation and the effects of the Great Depression of the 1920s. After the massive upheaval of the Second World War, the landscape was unimaginably different [...]. (MUSSON, 2010, p. 156). ${ }^{11}$

As consequências desses eventos históricos afetariam mais tarde a forma como o narrador-personagem recordaria o passado, não mais como um mordomo que serviu uma grande casa, mas como alguém que estava ao lado de um traidor do projeto antinazista de nação inglesa. Lorde Darlington pretendia uma anistia ao governo alemão e aparece na narrativa alinhado à ideologia de Hitler. Assim, Stevens deve sempre obedecer Lorde Darlington partindo do princípio que é seu mordomo e não deve abandonar o véu de sua profissão em nenhum momento. Para Candau (2011), memória e identidade estão indissoluvelmente conectadas. Em virtude disso, a identidade que Stevens assume como mordomo em Darlington Hall tem um impacto significativo sobre a forma como ele se lembra de Lorde Darlington, inicialmente, de forma saudosista.

Para o teórico Pierre Nora (1989):

Memory is life, borne by living societies founded in its name. It remains in permanent evolution, open to the dialectic of remembering and forgetting, unconscious of its successive deformations, vulnerable to manipulation and appropriation, susceptible to being long dormant and periodically revived. (NORA, 1989, p. 8, traduzido por Roudebush). ${ }^{12}$

A memória individual de Stevens - suas recordações pessoais - se integra com a memória coletiva - memória do contexto social da I e II Guerras Mundiais. O protagonista, no entanto, parece encontrar dificuldades em alinhar suas lembranças às de outros testemunhos fora de seu círculo social. Isso vai ao encontro da teoria de Halbwachs (2017) de que o depoimento de uma testemunha só teria sentido quando posto em relação a um grupo do qual ele faz parte. Esse depoimento pressupõe a vivência de um evento real que foi compartilhado por outros. Além disso, para que a memória de um indivíduo se aproveite da memória de outros vetores, não basta que estes apresentem a ele seus testemunhos: “[...]

11 Embora muitas casas continuassem a empregar funcionários na mesma quantidade como antes [...] o número diminuiu gradualmente, com novos choques após a taxação, inflação e os efeitos da Grande Depressão da década de 1920. Após a grande reviravolta da Segunda Guerra Mundial, a paisagem era inimaginavelmente diferente. (MUSSON, 2010, p. 156, tradução livre).

12 Memória é vida, carregada pelas sociedades existentes fundadas em nome dela. Permanece em evolução permanente, aberta à dialética do lembrar e esquecer, inconsciente de suas deformações sucessivas, vulnerável à manipulação e apropriação, suscetível de permanecer adormecida por muito tempo e reviver periodicamente. (NORA, 1989, p. 8, tradução livre). 
também é preciso que ele não tenha deixado de concordar com as memórias deles [...]." (HALBWACHS, 2017, p. 39).

Assim Halbwachs (2017) explica que o indivíduo participa de dois tipos de memória, a memória individual e a coletiva:

Admitamos, todavia, que haja, para as lembranças, duas maneiras de se organizar e que possam ora se agrupar em torno de uma pessoa definida, que as considere de seu ponto de vista, ora distribuir-se no interior de uma sociedade grande ou pequena, de que elas são outras tantas imagens parciais. (HALBWACHS, 2017, p. 35).

Ao deixar Darlington Hall para trás, Stevens pode enfim dialogar com integrantes (testemunhas) de outras camadas da sociedade. "É comum que imagens [...] impostas pelo meio em que vivemos, modifiquem a impressão que guardamos de um fato antigo, de uma pessoa outrora conhecida." (HALBWACHS, 2017, p. 32). Destaca-se, por exemplo, a cena em que o narrador-personagem, encontra com diferentes personagens em um bar após seu veículo ficar encalhado na estrada. Nesse local, Stevens dá-se conta de que poderia estar equivocado quanto à forma como lembrava-se de Lorde Darlington, como um homem grande e respeitável. Além disso, o protagonista acreditou, durante muito tempo, que mesmo atuando nos "bastidores" como mordomo de Lorde Darlington, ele ainda assim estaria contribuindo significativamente para a consolidação do projeto de nação da Inglaterra: "What happens within this house after that may have considerable repercussions [...]. On the whole course Europe is taking." (ISHIGURO, 1989, p. 62). ${ }^{13}$ No entanto, ao confrontar outros indivíduos, sua percepção sobre o passado e a história da Inglaterra se mostra equivocada. Os depoimentos dos outros são responsáveis por se incorporarem às lembranças do mordomo e corrigi-las e/ou reorientá-las. Dessa maneira, as outras personagens secundárias com quem Stevens se comunica ajudam-no gradualmente a reconstruir um quadro mais completo sobre o passado.

A visão subjetiva do mordomo, ou seja, sua memória individual diverge daquela da coletividade. Isso, segundo Halbwachs é comum pois a memória individual quando colocada no conjunto da memória coletiva pode mudar. Para Stevens, a comunidade inglesa está errada quanto a Lorde Darlington ser considerado nazista: "A great deal of nonsense has been spoken and written in recent years concerning his lordship and the prominent role he came to play in great affairs [...]." (ISHIGURO, 1989, p. 61). ${ }^{14}$

Para Halbwachs (2017):

Em sociedades de qualquer natureza que os homens formem entre si, quantas vezes não acontece que um deles deixe de ter uma ideia exata do lugar que ocupa no

13 “O que irá acontecer dentro dessa casa deverá ter repercussões consideráveis [...]. Em todo o rumo que a Europa está tomando." (ISHIGURO, 1989, p. 75).

14 "Uma grande quantidade de absurdos tem sido falada e escrita nos últimos anos sobre o seu senhorio e o papel proeminente que ele veio a desempenhar em grandes assuntos [...].” (ISHIGURO, 1989, p. 61). 
pensamento dos outros - de quantos mal-entendidos e desilusões tal diversidade de pontos de vista não será a fonte? (HALBWACHS, 2017, p. 35).

Stevens acredita ainda que Lorde Darlington não mantinha inclinações antissemitas, irritado com as notícias em torno de seu ex-patrão que terminam por denegrir sua própria imagem também. "[...] nonsense is to claim that Lord Darlington was anti-Semitic [...]. And the allegation that lordship never allowed Jewish people to enter the house or any Jewish staff to be employed is utterly unfounded [...]." (ISHIGURO, 1989, p. 137). ${ }^{15}$ No entanto, seu discurso se mostra contraditório ao passo que a narrativa avança: "[...] I remember his instructing me to cease giving donations to a particular local charity which regularly came to the door on the grounds that the management committee was 'more or less homogeneously Jewish'." (ISHIGURO, 1989, p. 146). ${ }^{16}$ Os esforços que o narrador-personagem emprega para defender a dignidade de Lorde Darlington terminam em vão. Lorde Darlington, em um episódio, pede que Stevens demita duas empregadas por serem judias. "I've been doing a great deal of thinking, Stevens. [...] We cannot have Jews on the staff here at Darlington Hall.'” (ISHIGURO, 1989, p. 146). ${ }^{17}$ O protagonista, mais tarde, percebe que o que acontecia por detrás daquelas paredes não tinha nada de "digno". Quando sua memória individual se alinha com a coletiva, percebe que o que considera o ápice de sua carreira tornou-se o fim de sua dignidade. Tudo o que parecia consolidado e em que o mordomo acreditou fielmente durante anos transforma-se metaforicamente em "pó”, "vestígios".

Para Halbwachs (2017), não é possível falar em lembranças que reapareçam sem poder relacioná-las a um grupo:

Talvez seja possível admitir que um número enorme de lembranças reapareça porque os outros nos fazem recordá-las; também se há de convir que, mesmo não estando esses outros materialmente presentes, se pode falar de memória coletiva quando evocamos um fato que tivesse um lugar na vida do nosso grupo e que víamos, que vemos ainda agora no momento em que recordamos, do ponto de vista desse grupo." (HALBWACHS, 2017, p. 41).

Stevens não percebe a gravidade dos acontecimentos históricos em torno da I e II Guerras Mundiais até sua memória se integrar com a coletividade, com a de outras testemunhas, grupos sociais ou vetores da rememoração. Neste trecho, o narrador-personagem, em um bar, acaba conversando com a população local de Devon e ouve um ponto de vista que

15 “[...] bobagem é afirmar que Lorde Darlington era antissemita [...]. E a alegação de que ele nunca permitiu que pessoas judias entrassem na casa ou que qualquer funcionário judeu fosse empregado é totalmente infundado [...]." (ISHIGURO, 1989, p. 137).

16 “[...] Lembro-me de ele ter me instruído a deixar de fazer doações para uma instituição de caridade local em particular, que vinha regularmente à porta alegando que o comitê administrativo era 'mais ou menos homogeneamente judaico."' (ISHIGURO, 1989, p. 146).

17 “'Eu tenho pensado muito, Stevens. [...] Não podemos ter judeus na equipe aqui em Darlington Hall”" (ISHIGURO, 1989, p. 146). 
a princípio o deixa incomodado. Hitler, que era uma figura importante para Lorde Darlington, é lembrado com desprezo por um personagem secundário:

That's what we fought Hitler for, after all. If Hitler had had things his way, we'd just be slaves now. The whole world would be a few masters and millions upon millions of slaves. And I don't need to remind anyone here, there's no dignity to be had in being a slave. (ISHIGURO, 1989, p. 186). ${ }^{18}$

Torna-se problemático o protagonista atribuir à noite em que Darlington Hall prestigiou uma reunião extraoficial - para a discussão de assuntos pertinentes ao rumo da Inglaterra e de seu envolvimento com a Alemanha Nazista - ao momento em que alcançou, segundo ele, a "dignidade" - ser merecedor, portanto, de desempenhar o papel de um mordomo em uma grande casa inglesa, a de Lorde Darlington:

[...] I have attained at least a little of that crucial quality of 'dignity' in the course of my career, such a person may wish to be directed towards that conference of March 1923 as representing the moment when I first demonstrated I might have a capacity for such a quality. (ISHIGURO, 1989, p. 70). ${ }^{19}$

O que Stevens narra é conveniente aos seus propósitos em oferecer um testemunho de sua história. O mordomo, até certo ponto, pretende convencer o leitor de que Lorde Darlington era uma vítima. À medida que as pessoas rejeitam Lorde Darlington, Stevens também se sente rejeitado vendo sua identidade sendo marginalizada. Consequentemente, nota-se que as memórias que o protagonista traz pretendem construir um quadro positivo sobre a imagem de seu antigo patrão. Dessa forma, o leitor inexperiente pode deixar-se convencer pela narração de Stevens em um primeiro momento: "It is, however, rather irksome to have to hear people talking today as though they were never for a moment taken in by Herr Ribbentrop." (ISHIGURO, 1989, p. 154). ${ }^{20}$ Shaffer (1998) afirma que: "[...] these first-person protagonists make for "unreliable," narrators, in Wayne Booth's influential term, who fail to speak for an act in accordance with the norms of the work, and who therefore are to be considered ironically in one way or another." (SHAFFER, 1998, p. 7). ${ }^{21}$ Ademais, Shaffer (1998) salienta que é evidente que os narradores-personagens de Ishiguro fingem estar oferecendo

18 É por isso que lutamos contra Hitler, afinal. Se Hitler tivesse feito as coisas do jeito dele, nós seríamos escravos agora. O mundo inteiro seria alguns mestres e milhões e milhões de escravos. E eu não preciso lembrar a ninguém aqui, não há dignidade em ser um escravo. (ISHIGURO, 1989, p. 186).

19 [...] eu alcancei pelo menos um pouco da tal qualidade crucial da 'dignidade' no decorrer da minha carreira. Essa pessoa poderá considerar a conferência de março de 1923 como representativa do momento em que demonstrei pela primeira vez possuir capacidade para tal qualificação. (ISHIGURO, 1989, p. 70).

20 "É, no entanto, um tanto cansativo ouvir as pessoas conversando hoje como se nunca tivessem sido, por um momento, enganadas por Herr Ribbentrop." (ISHIGURO, 2016, p. 154).

21 “[... esses protagonistas em primeira pessoa fazem de narradores "não confiáveis", no influente termo de Wayne Booth, que falham em falar em um ato de acordo com as normas do trabalho e que, portanto, devem ser considerados ironicamente de uma forma ou de outra." (SHAFFER, 1998, p. 7, tradução livre) 
um quadro real e preciso do que foi o passado quando, na verdade, trata-se de uma ilusão. Logo, o caso do narrador-personagem de The remains of the day não é diferente.

O processo de rememorar a própria vida, no caso de Stevens, revela a incapacidade do próprio narrador-personagem de relembrar com precisão cenas de seu passado. Isso é um fator comum, visto que, para Halbwachs (2017), a memória diz respeito a um processo de reconstrução e não de uma repetição linear de fatos. Nesta cena, a memória de Stevens se revela ambígua. É incapaz de dizer se fora Kenton ou Lorde Darlington quem lhe informou a respeito das circunstâncias da queda de seu pai: "But now that I think further about it. I am not sure Miss Kenton spoke quite so boldly that day. [...] I am not sure she could actually have gone so far as to say things like [...]." (ISHIGURO, 1989, p. 60). ${ }^{22}$ Para Izquierdo (2011, p. 19), "Nossa memória pessoal e coletiva descarta o trivial e, às vezes, incorpora fatos irreais. Vamos perdendo, ao longo dos dias e dos anos, aquilo que não interessa, aquilo que não nos marcou [...]." Ou seja, é possível também a incorporação de mentiras:

I cannot remember just what purpose had taken me up on to the top floor of the house to where the row of guests bedrooms line the corridor. But as I think I have said already, I can recall vividly the way the last of the daylight was coming through each open doorway and falling across the corridor in orange shafts. (ISHIGURO, 1989, p. 66). ${ }^{23}$

Assim, falhas na recordação de Stevens aparecem com recorrência sinalizando, portanto, sua incoerência e incapacidade de produzir um quadro completo dos fatos/eventos. Isso vai ao encontro do que Izquierdo (2011, p. 40) defende: "Pode-se afirmar, com certeza, que esquecemos a imensa maioria das informações que alguma vez foram armazenadas." Como Schacter (2001) também afirma, a memória não é fotográfica, mas "plástica”, ou seja, pode ser constantemente moldada, o que pode ser perfeitamente conectado aos excertos anteriores:

We then recreate or reconstruct our experiences rather than retrieve copies of them. Sometimes, in the process of reconstructing we add on feelings, beliefs, or even knowledge we obtained after the experience. In other words, we bias our memories of the past by attributing to them emotions or knowledge we acquired after the event. (SCHACTER, 2001, p. 9). ${ }^{24}$

\footnotetext{
22 "Mas agora que penso mais sobre isso. Não tenho certeza se Miss Kenton falou tão audaciosamente naquele dia. [...] não tenho certeza se ela poderia ter chegado ao ponto de dizer coisas como [...]." (ISHIGURO, 1989, p. 60).

23 Não me lembro exatamente o que possa ter me levado ao andar superior da casa, onde a fileira de quartos de hóspedes se alinhava no corredor. Mas, como acho que já disse, lembro-me vividamente do modo como o último raio de luz do dia entrava através de cada porta aberta. (ISHIGURO, 1989, p. 79).

24 Recriamos ou reconstruímos nossas experiências em vez de recuperar cópias delas. Às vezes, no processo de reconstrução, acrescentamos sentimentos, crenças ou mesmo conhecimento que obtivemos após a experiência. Em outras palavras, distorcemos nossas memórias do passado atribuindo a elas as emoções ou conhecimentos que adquirimos após o evento. (SCHACTER, 2001, p. 9, tradução livre).
} 
$\mathrm{Na}$ viagem de Stevens pelo Oeste Inglês, o mordomo não viaja só. Sua memória está conectada à mansão Darlington Hall, às pessoas que conheceu lá, aos livros de viagem e enciclopédias que consultou antes de deslocar-se. Isso ratifica a afirmação de Halbwachs (2017, p. 31), que aponta que jamais o indivíduo está só: "Para confirmar ou recordar uma lembrança, não são necessários testemunhos no sentido literal da palavra, isto é, indivíduos presentes sob uma forma material e sensível." Ou seja, Stevens viaja sozinho apenas em aparência. Sua memória individual ainda é representada conectada a uma teia de relações - a memória coletiva - que mantém com outras pessoas, grupos, espaços, ideias, etc. Halbwachs (2017) interroga-se: "Suponhamos que eu passeie sozinho. Será que se poderá dizer que deste passeio guardarei apenas lembranças individuais, só minhas? Contudo, apenas em aparência passeei sozinho. (HALBWACHS, 2017, p. 30). Assim, segundo Halbwachs (2017, p. 32): "Inversamente, pode acontecer que os testemunhos dos outros sejam os únicos exatos, que eles corrijam e rearranjem a nossa lembrança e ao mesmo tempo se incorporem a ela." Ou seja, não se deve descartar as imagens registradas pelo Outro a fim de se obter um quadro mais completo na representação do passado.

\section{CONSIDERAÇÕES FINAIS}

Este trabalho revela que a memória em The remains of the day, de Kazuo Ishiguro, não é um reflexo da testemunha do narrador-personagem e que a verdade permanece nas entrelinhas. É no choque entre Stevens e outros personagens que Ishiguro explora os confins da memória. Ou seja, é por meio do que não é dito que se percebe o real significado por detrás da narração de Stevens. Embora haja precisão na descrição de fatos/eventos do passado, trata-se de uma encenação com o objetivo de convencer o leitor e, portanto, obter sua aprovação. Assim, a obra convida a refletir sobre diversos aspectos da memória, sua natureza lábil, plástica, suas falhas, ambiguidades, representação e também sobre sua dimensão social, visto que a memória não pode existir desconexa dela. Stevens, durante toda a sua vida, passou a definir a si mesmo com base em referências ligadas a sua profissão como mordomo: Farraday, a influência profissional de seu pai, a Sociedade Hayes, etc. Ou seja, sua identidade foi, em grande parte, construída em cima de pilares que aos poucos foram desmoronando pela erosão do tempo. A mansão Darlington Hall nunca mais voltaria a ser a mesma: com seu grande número de empregados, como palco de encontro de aristocratas e políticos influentes, ou como bastidor de decisões que afetariam o rumo de toda a Europa. As duas grandes Guerras Mundiais abalaram as estruturas da organização social e econômica deixando para trás uma Inglaterra devastada. Então muito do que Stevens conhecia sobre o mundo passaria a existir somente em suas lembranças. Dessa forma, o protagonista passa grande parte da narrativa rememorando pessoas, lugares, fatos e eventos que possam acrescentar algum significado e sentido a sua situação presente, de melancolia, deslocamento e ansiedade. O narrador-personagem agora não consegue dialogar com o novo conjunto de ideias/crenças/valores com os quais é confrontado. Ao buscar estrutura em memórias de "dias grandiosos", Stevens se depara com um passado repleto de erros que só passaram a ser percebidos a partir de uma perspectiva presente, de uma perspectiva memorialista coletiva. 
Isso revela uma descontinuidade de sua memória individual com a memória coletiva dos grupos sociais com os quais interage - pequenas comunidades inglesas. Lorde Darlington, de uma perspectiva presente e coletiva, já não representa mais a imagem que ilustra um projeto de nação inglesa, mas a vergonha de um traidor de seu povo por simpatizar com a causa nazista. Quando seu novo empregador (um americano rico e representante da nova ordem da Europa do pós-guerra) incita Stevens a tirar umas férias, o protagonista é forçado a confrontar as consequências das decisões de sua vida. O narrador-personagem, por um curto período de tempo, se permite pensar e agir fora das paredes e muros de Darlington Hall (que metaforicamente representam os próprios limites da consciência do personagem e de sua memória individual). Sem seus rituais domésticos para mantê-lo ocupado, sua consciência se desdobra revelando memórias reprimidas pela pressão da sua condição profissional. O filosofar de Stevens sobre a "dignidade” e o que isso significa para sua postura e posição finalmente desmorona, e ele admite suas próprias falhas pessoais com a ex-governanta Kenton - que representaria uma chance utópica de redenção e felicidade. Ele se agarra ao fantasma da superioridade inglesa que provou ser ilusória. Stevens se lembra da imponente narrativa de seu pai há muito falecido, mas é forçado também a lembrar de um homem imprestável e doente ao final de sua vida. A impressão é que o protagonista reconstrói sua história pessoal para torná-la mais palatável, tanto para ele quanto para seu leitor. Essa estratégia revela também a plasticidade da memória, visto que ela é sempre uma reconstrução do passado e expõem a confiabilidade ilusória da narração de Stevens. A forma que narrador-personagem rememora é influenciada pelo presente, sobretudo, pelo peso de emoções reprimidas. O texto evidencia, portanto, um dos problemas centrais da memória, sua confiabilidade, pois o narrador-personagem quase nunca admite estar equivocado quanto à reconstrução de fatos/eventos. O sentimento de nostalgia contribui para a construção de uma narrativa do "eu", portanto, idealizada. Dessa forma, suas memórias divergem da forma como outros indivíduos, grupos (as pequenas comunidades inglesas) ou vetores rememoram o passado. Ou seja, as testemunhas tornam-se responsáveis por enfraquecerem o relato de Stevens. Dessa forma, é por meio, principalmente, do choque do protagonista com outros vetores memorialistas que Ishiguro explora o tema da memória.

\section{Referências}

ARISTÓTELES. Da memória e da reminiscência. Trad. de Marcus Thomazin. $1^{\circ}$. ed. SP: Amazon, 2019.

CANDAU, J. Memória e identidade. Trad. de Maria Leticia Ferreira. $1^{\circ}$. ed. SP: Contexto, 2008.

COMPAGNON, A. O demônio da teoria. Trad. de Cleonice Paes Barreto Mourão e Consuelo Fortes Santiago. $2^{\circ}$. ed. MG: UFMG, 2014.

DUVIGNAUD, J. Introdução. In: HALBWACHS, M. A memória coletiva. Trad. de Beatriz Sidou. $2^{\circ}$. ed. SP: Centauro, 2017. p. 17-23. 
ERLL, A. Cultural memory studies: An introduction. In: ERLL, A.; NÜNNING, A. (Org.). Cultural memory studies: An international and interdisciplinary handbook. $1^{\circ}$. ed. NY: de Gruyter, 2008. p. $1-15$.

GRANJA, C. S. Los personajes de Kazuo Ishiguro: En busca de respuestas en el pasado. Revista Cuadernos Canela, v. 26, p. 9-23, mai. 2015. Disponível em: <http://cuadernoscanela.org/index.php/ cuadernos/article/view/48>. Acesso em: 3 jul. 2019.

HALBWACHS, M. A memória coletiva. Trad. de Beatriz Sidou. $2^{\circ}$. ed. SP: Centauro, 2017.

HOMERO. A ilíada. Trad. de Frederico Lourenço. 1º. ed. SP: Penguin, 2013.

ISHIGURO, K. The remains of the day. $1^{\circ}$. ed. NY: Vintage Books, 1989.

IVERSEN, Y. The remains of the day: Tradition and the individualist survivor. 58 f. 2014. Dissertação (Mestrado em Literatura Inglesa) - Universidade de Agder, Noruega, 2014.

IZQUIERDO, I. Memória. 2º . ed. RS: Artmed, 2011.

JOHANSSON, K. The self-contradictory narrative of Mr Stevens in Kazuo Ishiguro's “The Remains of the Day”. Suécia: Biblioteca da Universidade de Gotemburgo, 2011. Resenha de: ISHIGURO, K. The remains of the day. Londres: Faber and Faber, 1989. Disponível em: <https://gupea.ub.gu.se/ bitstream/2077/25883/1/gupea_2077_25883_1.pdf>. Acesso em: 3 jul. 2019.

MIYOSHI, M. et al. Japan in the world. $1^{\circ}$. ed. Carolina do Norte: Duke University Press, 1999.

MUSSON, J. Up and down stairs. $1^{\circ}$. ed. Londres: John Murray Publisher, 2010.

NEUMANN, B. The literary representations of memory. In: ERLL, A.; NÜNNING, A. (Org.). Cultural memory studies: An international and interdisciplinary handbook. $1^{\circ}$. ed. NY: de Gruyter, 2008. p. 333-343.

RAY, K. S. Memory and Kazuo Ishiguro's novels: A review. 2017. Revista Literary Herald, Índia, v. 2, n. 4, p. 293-309, Mar. 2017. Disponível em: <http://tlhjournal.com/uploads/products/38.kasturi-sinharay-article1.pdf>. Acesso em: 3 jul. 2019.

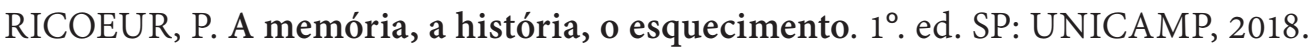

SHAFFER, B. W. Understanding Kazuo Ishiguro. $1^{\circ}$. ed. Columbia: University of South Carolina Press, 1998.

UMBACH, R. K. Memórias da repressão e literatura: Algumas questões teóricas. in: UMBACH, R. K

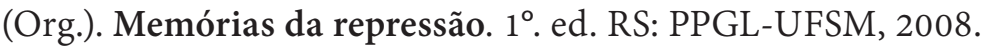


USUI, M. Lost and found: A voice retrieved from the Holocaust in Kazuo Ishiguro's. Revista Doshida de Estudos em Inglês, Japão, n. 95, p. 69-93, 2015. Disponível em: <https://doors.doshisha.ac.jp/duar/ repository/ir/22840/?lang=0>. Acesso em: 3 jul. 2019.

VIRGÍlIO. Eneida. Trad. de Carlos Alberto Nunes. 2º ed. SP: 34, 2016.

WINTER, J. A geração da memória: Reflexões sobre o "boom da memória” nos estudos contemporâneos de história. Trad. de Claudia Valladão de Mattos. In: SELIGMANN-SILVA, M. (Org.). Palavra e imagem, memória e escritura. $1^{\circ}$. ed. Chapecó: Argos, 2006. p. 67-90. 
